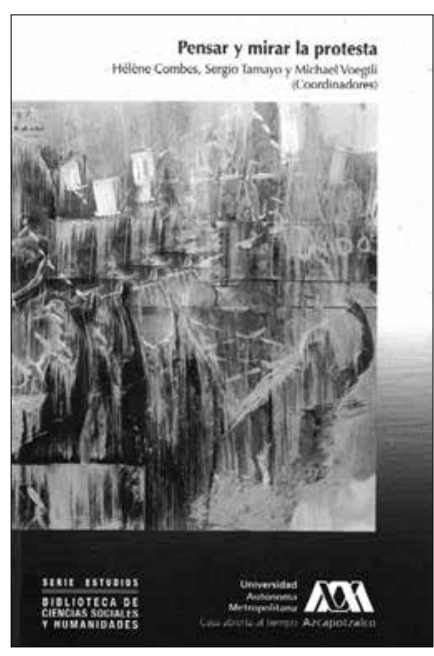

- Pensar y mirar la protesta

Hélène Combes, Sergio Tamayo

Y MichaEL VoegtLI (COORDS.), 2016

Universidad Autónoma Metropolitana-

Azcapotzalco, México

\title{
Movilizaciones y eventos de protesta en México, un análisis comparado
}

\author{
TOMMASO GRAVANTE
}

Mobilization and Protest

Events in Mexico,

a Comparative Analysis

TOMMASO GRAVANTE

Laboratorio de Análisis de

Organizaciones y Movimientos Sociales, Centro de Investigaciones Interdisciplinarias en Ciencias y Humanidades, Universidad

Nacional Autónoma de México,

Ciudad de México, México

t.gravante@gmail.com

Desacatos 57 ,

mayo-agosto 2018, pp. 208-211 a insurgencia popular de Oaxaca, México, en 2006, definida también como "la primera insurrección del siglo Xxi", abrió un ciclo de experiencias de protestas en los años que siguieron en muchas regiones del mundo. A pesar de sus diferencias socioculturales, estas manifestaciones se caracterizaron por compartir aspectos como la deslegitimación del sistema democrático/régimen autoritario, la participación masiva de las clases populares y las prácticas innovadoras de autogestión sociopolítica, por un lado, y la legitimación y uso militar por parte de los representantes políticos de los aparatos represivos, de las redes de delación y cooptación, por el otro.

Con la experiencia de Oaxaca, las protestas que emergieron desde 2008 — primero en Islandia y Grecia, con la cúspide de 2011 en España y Estados Unidos, entre otros - se produjeron por una combinación de elementos que hasta entonces sólo se habían visto e investigado en determinados momentos históricos — como 1968- o experiencias aisladas en los estudios de los movimientos sociales. Por 
ejemplo, destaca la reciente literatura: el componente populista de las demandas, la evocación de una resistencia pacífica, las estrategias de resistencia violenta, las prácticas de netactivismo, la apropiación o reapropiación de espacios públicos, la formación de redes con grupos muy diferentes entre sí y el involucramiento de una amplia y heterogénea base social, muchas veces sin experiencia política previa.

La efervescencia social de 2011 se ha manifestado también en una reactivación y discusión en los estudios sobre la acción colectiva, los cuales llegaron a un estancamiento teórico-analítico después de la implosión del así llamado movimiento altermundista. Las manifestaciones masivas en más de diez países árabes del norte de África, Hong Kong, Singapur, Tokio, Estados Unidos, México, Chile y parte de Europa, entre otros, han sublevado la emergencia de comprender cómo puede innovarse el estudio de la protesta y enfocarlo en ciertos aspectos de la movilización, como los efectos de las marchas en los participantes o en la transformación del pensamiento político. Con estas inquietudes, emergen proyectos de investigación como "Mobilizing for Democracy", dirigido por Donatella della Porta, y "Contextualizing Contestation: Caught in the Act of Protest", de Donatella della Porta, Lorenzo Bosi y Massimiliano Andretta, ambos en Italia; "Processus et acteurs latino-américains de la participation politique" (PALAPA), coordinado por Camille Goirand en Francia, y redes de investigadores de los movimientos sociales, como el Centre on Social Movement Studies (COsmos) de la Scuola Normale Superiore de Florencia, o la Red Mexicana de Estudios de los Movimientos Sociales, así como decenas de publicaciones con enfoques diversos sobre las experiencias de protesta de esos años. ${ }^{1}$

Pensar y mirar la protesta, coordinado por Hélène Combes, Sergio Tamayo y Michael Voegtli, emerge de estas inquietudes y ofrece claves para el estudio y la comprensión de las protestas que han caracterizado estos años de alta conflictividad social. ${ }^{2}$
La importancia de este texto reside en que, con el trabajo de Donatella della Porta (2015), representa uno de los pocos balances acerca de dónde estamos en el estudio sociológico de la acción colectiva y cómo nos acercamos como investigadores a este fenómeno social.

El punto de partida del libro son los resultados de investigación del Seminario Internacional "Pensar y mirar la protesta", organizado por los coordinadores en 2011, en la Ciudad de México, enriquecidos con el inusual e interesante diálogo entre algunos representantes de la escuela francesa, como Olivier Fillieule y Hélène Combes, con algunos de los especialistas más destacados en el estudio de la acción colectiva en México, como Sergio Tamayo.

La obra colectiva, compuesta por 12 capítulos, se organiza en tres secciones. La primera parte nos introduce en los estudios sobre las movilizaciones y los eventos de protesta. El texto de Olivier Fillieule, que abre la sección, hace un balance a partir de sus 20 años de investigación en este campo de estudio. El capítulo de Camille Goirand nos permite comprender qué perspectivas científicas sobre las movilizaciones y la participación han emergido en Latinoamérica y cómo dependen, por un lado, de las características organizacionales e ideológicas de los movimientos populares que emergieron en el continente, y por el otro, de una toma de posición política y compromiso asumidos por los investigadores. Para el lector experto es interesante ver cómo la investigadora arroja luz sobre los procesos de institucionalización de los movimientos sociales y la

Véanse: <http://cosmos.sns.it/projects/mobilizing-for-demo cracy/>, <http://cosmos.sns.it/projects/contextualizing-con testation-caught-in-the-act-of-protest/>; <https://www.ird. $\mathrm{fr} /$ infos-pratiques/archives/anciens-programmes-de-sou tien/les-suds-aujourd-hui/liste-des-projets-soutenus/pa lapa-processus-et-acteurs-latino-americains-de-la-partici pation-politique>.

2 Combes y Tamayo coordinan el proyecto PALAPA en México. 
manera en que la participación se ha convertido en un imperativo de la acción pública.

En la segunda sección se presentan varios acercamientos a la protesta. Los análisis que la conforman representan una importante contribución al debate que hemos relatado. El apartado comienza con el texto de Abilio Vergara Figueroa, que mira la protesta a través de su producción expresiva. Compara diversos movimientos sociales y relata cómo la construcción simbólica de las experiencias analizadas y sus escenificaciones, relatos y rituales construyen una ética que se expresa en una estética que se distingue por el uso del cuerpo como arma de lucha y en una política de lo cotidiano.

Marie-Laure Geoffray, con el análisis de la dimensión situada de la contestación, se propone estudiar los modos de acción que caracterizan el repertorio de la contestación en el contexto autoritario cubano, en espacios urbanos físicos y virtuales. En la primera parte de su texto, analiza cómo las microarenas fragmentadas de actuación colectiva permiten la creación de territorios en los cuales pueden emerger espacios de libertad de expresión y crítica. La segunda parte del capítulo constituye un análisis de geografía virtual de la contestación en el joven mundo digital cubano. Más allá del uso metafórico de la noción de espacio, el texto destaca la posibilidad de reflexionar sobre los procesos de apropiación, localización e identificación tanto del espacio real como de aquel constituido por bites.

El trabajo de Aysen Uysal reviste una originalidad por el tema de mirar la protesta desde las bases de datos policiacos. En su caso, el punto de partida son los archivos policiacos de las acciones de protesta de la Dirección General de la Policía de Ankara, en Turquía. El texto es un interesante ejemplo —entre pocos - para el investigador que quiere utilizar este tipo de fuente documental, aunque todavía no está claro cómo codificar las formas de clasificación de la policía de "eventos sociales", sobre todo en casos de enfrentamientos violentos.
Esta sección cierra con la investigación de Nicolasa López Saavedra, que propone la mirada de la protesta por su representación en medios de comunicación: prensa escrita, radio y televisión, línea de investigación poco tratada en México. Destaca el enfoque metodológico innovador que López Saavedra propone, al tomar en cuenta las palabras de quienes procesan y construyen la información mediática.

La tercera sección, más que presentar estudios de caso, es una aportación orgánica al debate actual sobre las propuestas teóricas en el estudio de la acción colectiva, a la luz de las experiencias de los últimos años. Las propuestas analíticas de los autores de este apartado combinan conceptos y teorías que, como sostienen los coordinadores, a veces pueden parecer contradictorios. La sección comienza con un texto de Michel Offerlé que recorre el estudio de las acciones colectivas de las elites económicas y las organizaciones patronales.

El capítulo que sigue, de Francis Mestries, nos remite a un campo clásico del estudio de la acción colectiva, el estudio de las organizaciones de los movimientos sociales (OMS). El caso que analiza es la evolución de la organización mexicana El Barzón, que emergió para defender a los medianos productores agrícolas insolventes de la banca y los agiotistas. En el escenario de la protesta social mexicana, marcado por el corporativismo y el liderazgo, reviste un papel importante el análisis de Mestries sobre estos tipos de organizaciones, que están en continua lucha por no convertirse en meros grupos de intereses y no ser absorbidos por el sistema que ellos mismos contestan.

No podía faltar, por su relevancia, un análisis de la experiencia que mencionamos al comienzo de esta reseña, el movimiento popular de Oaxaca. Silvia Bolos, experta conocida en el estudio del caso, propone un mapa de los actores del conflicto y sus formas de interactuar. Según ella, esta geografía se conforma alrededor de dos proyectos que 
caracterizaron el conflicto oaxaqueño: una transformación institucional de los actores involucrados y una transformación radical de la sociedad.

El trabajo de Sergio Tamayo y Ricardo Torres trata uno de los temas que sigue siendo poco estudiado en la acción colectiva, es decir, el análisis de la apropiación social del espacio de la protesta. La investigación considera como caso de estudio la marcha del Movimiento Nacional en Defensa de la Economía Popular, el Petróleo y la Soberanía, del 23 de noviembre de 2008, en México. Los dos investigadores de la Universidad Autónoma Metropolitana-Azcapotzalco no sólo hacen un mapeo de los participantes, también se enfocan en por qué se manifiestan y cómo lo hacen, y ponen énfasis en el análisis de la valoración de eficacia que los propios participantes dan a sus acciones y el compromiso con el movimiento social. Los resultados de Tamayo y Torres muestran que el análisis de la apropiación social de un espacio público contribuye a comprender cómo se construye una determinada forma de discurso político, una identidad colectiva y una cultura política específicas.

Hélène Combes parte de su experiencia de más de 13 años en la investigación del funcionamiento interno y el entorno partidista del Partido de la Revolución Democrática (PRD) en México. En su capítulo, se enfoca en las movilizaciones alrededor del "gobierno legítimo" que comenzaron después de las elecciones presidenciales de 2006. Entre otras cosas, es interesante ver cómo el
PRD se estructura para diversificar el reclutamiento militante.

El apartado concluye con el trabajo de $\mathrm{Mi}-$ chael Voegtli. El investigador suizo nos lleva a otro problema que sacude los movimientos sociales: el proceso de despolitización que vive la experiencia de protesta, muchas veces acompañado por un institucionalización o cooptación. Voeglti analiza las marchas del movimiento lésbico, gay, bisexual, transexual, transgénero, travesti e intersexual (LGBTtTi) en la Ciudad de México y habla de un doble proceso de despolitización: primero, respecto al perfil de los participantes en términos de competencia política; segundo, en cuanto a los aspectos de la vida social. Según el autor, en estos procesos se refleja una transformación de la identidad colectiva del movimiento social.

Pensar y mirar la protesta se presenta como una obra compleja cuyos capítulos se articulan sobre las tres principales dimensiones del estudio de la protesta: una dimensión metodológica, una analítica y una teórica. Por la complejidad y profundidad con las que son tratadas estas dimensiones, al concluir la lectura del libro consideramos que faltó un epílogo en el que los coordinadores destacaran las propuestas y los resultados que han emergido de las contribuciones. A pesar de esto, el texto representa un esfuerzo único que nos da la oportunidad, como investigadores de la acción colectiva, de pensar y mirar estas experiencias desde una perspectiva multidimensional y acercarnos a otras formas de indagación. D

\section{Bibliografía}

Porta, Donatella della, 2015, Social Movements in Times of Austerity: Bringing Capitalism Back into Protest Analysis, Polity Press, Cambridge. 